\title{
Retrievals of chlorine chemistry kinetic parameters from Antarctic CIO microwave radiometer measurements
}

\author{
S. Kremser ${ }^{1,8}$, R. Schofield ${ }^{2}$, G. E. Bodeker ${ }^{1, *}$, B. J. Connor ${ }^{3}$, M. Rex ${ }^{2}$, J. Barret ${ }^{4}$, T. Mooney ${ }^{4}$, R. J. Salawitch ${ }^{5}$, \\ T. Canty ${ }^{5}$, K. Frieler ${ }^{6}$, M. P. Chipperfield ${ }^{7}$, U. Langematz ${ }^{8}$, and W. Feng ${ }^{7}$ \\ ${ }^{1}$ National Institute of Water and Atmospheric Research, Lauder, New Zealand \\ ${ }^{2}$ Stiftung Alfred-Wegener Institut (AWI), Forschungsstelle Potsdam, Potsdam, Germany \\ ${ }^{3}$ BC Consulting Ltd., Alexandra, New Zealand \\ ${ }^{4}$ Stony Brook University, Stony Brook, New York, USA \\ ${ }^{5}$ Department Atmosphere \& Ocean Science, University of Maryland, Maryland, USA \\ ${ }^{6}$ Potsdam Institute for Climate Impact Research (PIK), Potsdam, Germany \\ ${ }^{7}$ Institute for Climate \& Atmospheric Science, School of Earth \& Environment, University of Leeds, Leeds, UK \\ ${ }^{8}$ Freie Universität Berlin, Berlin, Germany \\ * now at: Bodeker Scientific, Alexandra, New Zealand
}

Received: 10 September 2010 - Published in Atmos. Chem. Phys. Discuss.: 4 November 2010

Revised: 13 May 2011 - Accepted: 17 May 2011 - Published: 1 June 2011

\begin{abstract}
Key kinetic parameters governing the partitioning of chlorine species in the Antarctic polar stratosphere were retrieved from 28 days of chlorine monoxide $(\mathrm{ClO}) \mathrm{mi}-$ crowave radiometer measurements made during the late winter/early spring of 2005 at Scott Base $\left(77.85^{\circ} \mathrm{S}, 166.75^{\circ} \mathrm{E}\right)$. During day-time the loss of the $\mathrm{ClO}$ dimer chlorine peroxide $(\mathrm{ClOOCl})$ occurs mainly by photolysis. Some time after sunrise, a photochemical equilibrium is established and the $\mathrm{ClO} / \mathrm{ClOOCl}$ partitioning is determined by the ratio of the photolysis frequency, $J$, and the dimer formation rate, $k_{\mathrm{f}}$. The values of $J$ and $k_{\mathrm{f}}$ from laboratory studies remain uncertain to a considerable extent, and as a complement to these ongoing studies, the goal of this work is to provide a constraint on that uncertainty based on observations of $\mathrm{ClO}$ profiles in the Antarctic. First an optimal estimation technique was used to derive $J / k_{\mathrm{f}}$ ratios for a range of $K_{\text {eq }}$ values. The optimal estimation forward model was a photochemical box model that takes $J, k_{\mathrm{f}}$, and $K_{\text {eq }}$ as inputs, together with a priori profiles of activated chlorine $\left(\mathrm{ClO}_{\mathrm{x}}=\mathrm{ClO}+2 \times \mathrm{ClOOCl}\right)$, profiles of ozone, temperature, and pressure. JPL06 kinetics are used as a priori in the optimal estimation and for all other chemistry in the forward model. Using the more recent JPL09 kinetics results in insignificant differences in the retrieved value of $J / k_{\mathrm{f}}$. A complementary approach was used
\end{abstract}

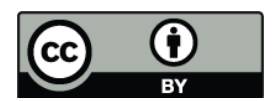

Correspondence to: $\mathrm{S}$. Kremser

(s.kremser@niwa.co.nz) to derive the optimal kinetic parameters; the full parameter space of $J, k_{\mathrm{f}}, K_{\text {eq }}$ and $\mathrm{ClO}_{\mathrm{x}}$ was sampled to find the minimum in differences between measured and modelled $\mathrm{ClO}$ profiles. Furthermore, values of $K_{\text {eq }}$ up to 2.0 times larger than recommended by JPL06 were explored to test the sensitivity of the $J / k_{\mathrm{f}}$ ratio to changes in $K_{\text {eq }}$. The results show that the retrieved $J / k_{\mathrm{f}}$ ratios bracket the range of 1.23 to 1.97 times the $J / k_{\mathrm{f}}$ value recommended by JPL06 over the range of $K_{\text {eq }}$ values considered. The retrieved $J / k_{\mathrm{f}}$ ratios lie in the lower half of the large uncertainty range of $J / k_{\mathrm{f}}$ recommended by JPL06 and towards the upper portion of the smaller uncertainty range recommended by JPL09.

\section{Introduction}

The photochemistry of the chlorine monoxide dimer, chlorine peroxide $(\mathrm{ClOOCl}$; hereafter "the dimer") in the polar stratosphere is central to quantitatively describing polar ozone depletion and hence the Antarctic ozone hole. The formation and photolysis of $\mathrm{ClOOCl}$, known as the $\mathrm{ClO}$ dimer cycle (Molina and Molina, 1987), is typically responsible for $55 \%$ to $70 \%$ of the spring-time ozone depletion in the Antarctic stratosphere (Frieler et al., 2006; SPARC, 2009). When high chlorine monoxide $(\mathrm{ClO})$ concentrations are present in the polar stratosphere, the $\mathrm{ClO}$ dimer cycle:

Published by Copernicus Publications on behalf of the European Geosciences Union. 


$$
\begin{gathered}
\mathrm{ClO}+\mathrm{ClO}+\mathrm{M} \underset{k_{\mathrm{r}}}{\stackrel{k_{\mathrm{f}}}{\rightleftarrows}} \mathrm{ClOOCl}+\mathrm{M} \\
\mathrm{ClOOCl}+h v \stackrel{J}{\rightarrow} \mathrm{Cl}+\mathrm{ClOO} \\
\mathrm{ClOO}+\mathrm{M} \rightarrow \mathrm{Cl}+\mathrm{O}_{2}+\mathrm{M} \\
2 \times\left[\mathrm{Cl}+\mathrm{O}_{3} \rightarrow \mathrm{ClO}+\mathrm{O}_{2}\right]
\end{gathered}
$$

$\mathrm{Net}: 2 \mathrm{O}_{3}+h v \rightarrow 3 \mathrm{O}_{2}$

becomes an extremely efficient ozone loss process. The terms $k_{\mathrm{f}}$ and $k_{\mathrm{r}}$ refer to the reaction rate constants for the formation and the thermal dissociation of the dimer, respectively. $M$ represents any molecule to remove excess energy and $J$ is the photolysis frequency of the dimer, which is directly related to the dimer absorption cross-section. Reactions (R2) and (R3) are the most important for ozone destruction since they release chlorine $(\mathrm{Cl})$ atoms that then react with ozone (Reaction R4). Reaction (R2) is the rate limiting step for loss of ozone in the cycle.

If $\mathrm{ClOOCl}$ decomposes thermally (Reaction $\mathrm{R} 1$ ) rather than being photolysed (Reaction R2), or if the photolysis reaction produces $\mathrm{ClO}$, a null cycle results that leads to no change in ozone. During day-time $\mathrm{ClOOCl}$ loss occurs mainly by photolysis and the partitioning between $\mathrm{ClO}$ and $\mathrm{ClOOCl}$, as well as the overall rate of the catalytic cycle, are controlled by the dimer formation rate $\left(k_{\mathrm{f}}\right)$ and photolysis frequency $(J)$. When sufficient time has passed after sunrise, the reaction system reaches a photochemical steady state, and the partitioning between $\mathrm{ClO}$ and $\mathrm{ClOOCl}$ is given by the expression:

$$
\frac{[\mathrm{ClO}]^{2}}{[\mathrm{ClOOCl}]} \sim \frac{J}{k_{\mathrm{f}}[\mathrm{M}]}
$$

During night-time the temperature dependent thermal equilibrium constant $K_{\text {eq }}$ governs the partitioning between $\mathrm{ClO}$ and $\mathrm{ClOOCl}$ :

$$
K_{\text {eq }}=\frac{k_{\mathrm{f}}}{k_{\mathrm{r}}}=\frac{[\mathrm{ClOOCl}]}{[\mathrm{ClO}]^{2}}
$$

Uncertainties in these kinetic parameters $\left(J, k_{\mathrm{f}}\right.$ and $\left.K_{\text {eq }}\right)$ contribute to differences between measured and modelled polar stratospheric $\mathrm{ClO}$ (e.g., Stimpfle et al., 2004), affect our ability to accurately describe polar ozone destruction (e.g., Frieler et al., 2006; von Hobe et al., 2007), and our ability to confidently project the response of polar ozone to future changes in stratospheric chlorine loading (e.g., SPARC, 2009).

Models of polar ozone photochemistry have traditionally used values of the $\mathrm{ClOOCl}$ absorption cross-section and $k_{\mathrm{f}}$ recommended either by the JPL data panel (e.g., Sander et al., 2003, 2006, 2009) or the IUPAC Subcommittee on Gas Kinetic Data Evaluation panel (Atkinson et al., 2007). Values of the $\mathrm{ClOOCl}$ cross-section recommended by the various panels typically fell between laboratory measurements by Huder and DeMore (1995) (low range in photolytically active region) and Burkholder et al. (1990) (high range). In 2007, Pope et al. published $\mathrm{ClOOCl}$ absorption crosssections that were considerably lower than either the Sander et al. (2006) (hereafter: JPL06) or Atkinson et al. (2007) recommendations. This lower photolysis frequency would make it impossible to quantitatively explain observed ozone loss with known chemistry, suggesting that as yet unknown processes were active. More recent laboratory studies by von Hobe et al. (2009), Chen et al. (2009), Papanastasiou et al. (2009), and Wilmouth et al. (2009) concluded that the correction applied by Pope et al. to account for $\mathrm{Cl}_{2}$ contamination in their $\mathrm{ClOOCl}$ sample may have been too large. This in turn would lead to cross-sections which are too small in the atmospherically important wavelength region $(>300 \mathrm{~nm})$. That said, these studies published in 2009 do not agree on the absorption cross-sections for the dimer, and so there remains uncertainty on the photolysis frequency for the $\mathrm{ClO}$ dimer. Comparisons between measured and modelled $\mathrm{ClO}$ (von Hobe et al., 2007; Schofield et al., 2008) concluded that no combination of $k_{\mathrm{f}}$ and $K_{\mathrm{eq}}$ was compatible with the absorption cross-sections measured by Pope et al. (2007).

Furthermore, field measurements of $\mathrm{ClO}$ and $\mathrm{ClOOCl}$ by von Hobe et al. (2007) and Stimpfle et al. (2004) and satellite measurements of $\mathrm{ClO}$ by Santee et al. (2010) indicate discrepancies in the equilibrium constant $K_{\text {eq }}$ for $\mathrm{ClOOCl}$ compared to the JPL06 recommendation, and the more recent JPL09 recommendation. Therefore, there is a need to reduce the uncertainties in these reaction kinetic parameters, and thereby reduce uncertainties in modelled polar ozone loss.

In this study, two methods, both using $\mathrm{ClO}$ microwave radiometer measurements from Scott Base $\left(78.85^{\circ} \mathrm{S}\right.$, $\left.166.75^{\circ} \mathrm{E}\right)$, Antarctica, during the late winter and early spring of 2005 (described in Sect. 2), are used to constrain the kinetic parameters governing $\mathrm{ClO}$ chemistry in the polar stratosphere, viz.:

1. An optimal estimation approach (Sect. 3), using a photochemical box model as a forward model, is used to derive optimal $J / k_{\mathrm{f}}$ ratios consistent with the measured $\mathrm{ClO}$ profiles.

2. An exploration of the $J, k_{\mathrm{f}}, K_{\mathrm{eq}}$ and $\mathrm{ClO}_{\mathrm{x}}$ $\left(\mathrm{ClO}_{\mathrm{x}}=\mathrm{ClO}+2 \times \mathrm{ClOOCl}\right.$, i.e. active chlorine $)$ parameter space, within physically plausible limits, to find where the minimum of measurement-model differences occurs.

The first approach is significantly faster than the second and provides statistical uncertainties on the derived parameters. The second, in addition to showing which set of parameters minimizes the measurement-model difference, also shows the regions within the $4 \mathrm{D}$-space (4 dimensions, i.e. $J, k_{\mathrm{f}}$, $K_{\text {eq }}$, and $\mathrm{ClO}_{\mathrm{x}}$ ) where differences of a similar magnitude are obtained. The second method also shows whether there are local minima in the 4-D-space that might provide a set of 
viable kinetic parameters consistent with the field observations. The results obtained are presented and compared with previously published results in Sect. 4. These results are discussed in Sect. 5, followed by the conclusion of this study in Sect. 6.

\section{Observations and model data}

\subsection{Observations}

Stony Brook University and National Institute of Water and Atmospheric research (NIWA) have jointly operated a ground-based $\mathrm{ClO}$ microwave radiometer at Scott Base, Antarctica, since February 1996. The instrument and the ClO measurements are described in more detail in Solomon et al. (2000) and Connor et al. (2007). Briefly, the microwave radiometer measures the thermally-excited emission of $\mathrm{ClO}$ at $278.6 \mathrm{GHz}$ within a frequency band of $506 \mathrm{MHz}$. As the $\mathrm{ClO}$ molecule has a very weak line amplitude, it is necessary to integrate the measured signals over some time period. Therefore, to generate the day-time and night-time $\mathrm{ClO}$ spectra, the individual $\mathrm{ClO}$ spectra, measured in $20 \mathrm{~min}$ time intervals, are averaged over the day-time and night-time period, respectively. Day-time is defined as $3 \mathrm{~h}$ after sunrise until $1 \mathrm{~h}$ before sunset at $20 \mathrm{~km}$ altitude, while night-time is defined as $4 \mathrm{~h}$ after sunset until $1 \mathrm{~h}$ before sunrise at $20 \mathrm{~km}$ altitude. The sunset and sunrise at $20 \mathrm{~km}$ altitude is defined by a solar zenith angle of $94.5^{\circ}$. An ozone line within the $\mathrm{ClO}$ microwave emission band interferes with the measurement. To eliminate this interference, and instrumental artefacts, the day minus night $\mathrm{ClO}$ spectrum is obtained by subtracting the mean night-time spectrum from the mean day-time spectrum. At night, Reaction (R1) dominates Reaction (R2), leading to most $\mathrm{ClO}_{\mathrm{x}}$ being in the form of $\mathrm{ClOOCl}$ and, as a result, depending on the day of the year, night-time $\mathrm{ClO}$ is less than $\sim 20 \%$ of day-time $\mathrm{ClO}$. The day minus night subtraction is essential for the analysis of the measured spectra to remove the ozone line and artefacts. The day minus night definitions were determined by detailed examination of spectra intensity relative to sunrise and sunset and the definition for day and night was chosen so that periods where $\mathrm{ClO}$ changes rapidly were avoided (Solomon et al., 2002).

$\mathrm{ClO}$ profiles from 10 to $56 \mathrm{~km}$ are derived from the $\mathrm{ClO}$ day minus night spectra. It should be noted that although the vertical resolution of the retrieved $\mathrm{ClO}$ profile is about $10 \mathrm{~km}$, the location of the peak in the $\mathrm{ClO}$ mixing ratio can be determined to an accuracy of 1 to $2 \mathrm{~km}$ (Solomon et al., 2000, 2006). Retrieved concentrations of $\mathrm{ClO}$ on 20 altitude levels from 11 to $30 \mathrm{~km}$ are used in this analysis because $\mathrm{ClO}$ reaches its maximum abundance within this range of altitude. Twenty-eight days of $\mathrm{ClO}$ profiles, made during the period from 21 August to 20 September 2005 (Fig. 1), are used in this study, as 2005 offered the most comprehensive dataset. Due to bad weather conditions there were no $\mathrm{ClO}$ measure-

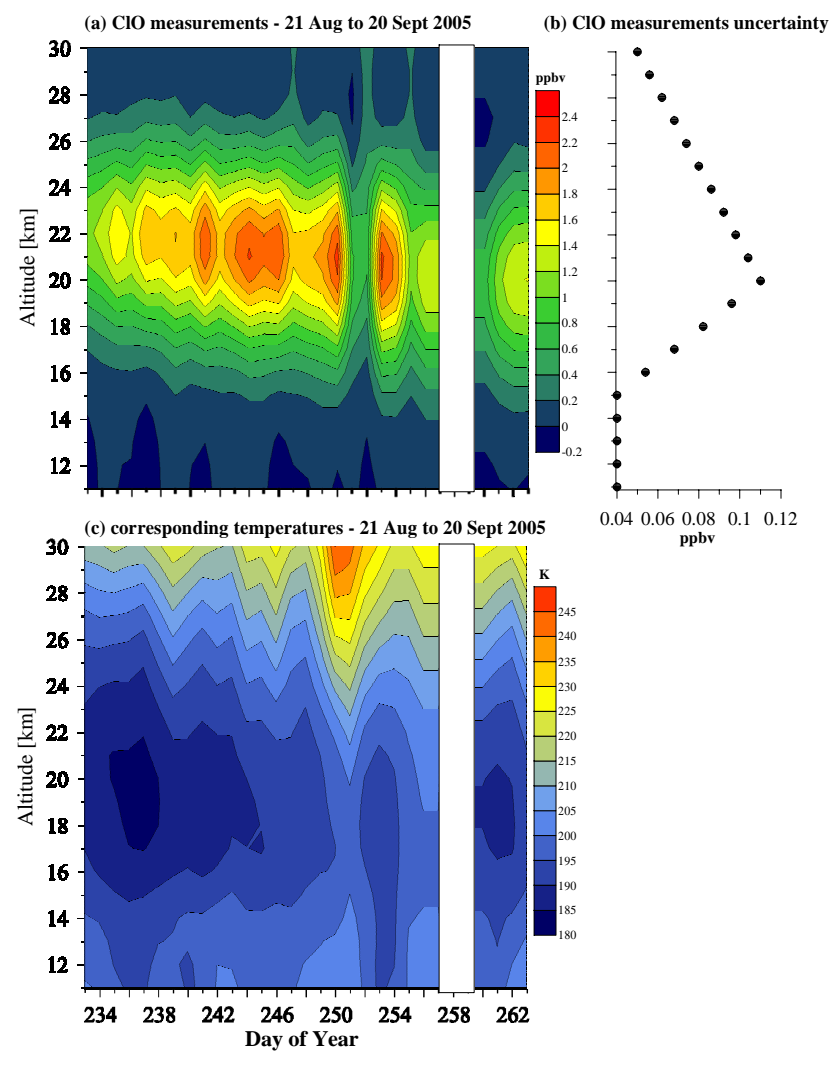

Fig. 1. Measured $\mathrm{ClO}$ concentrations in ppbv (panel a), the corresponding errors (panel $\mathbf{b}$ ) and the coincident temperatures in $\mathrm{K}$ (panel c) plotted as a function of altitude and day of the year in 2005. The blue and organge/red colours in panel (a) depict low $\mathrm{ClO}$ concentrations (below $0.2 \mathrm{ppbv}$ ) and high $\mathrm{ClO}$ concentrations (above $1.6 \mathrm{ppbv}$ ), respectively. In panel (c), low temperatures (below $210 \mathrm{~K}$ ) are indicated by the blue colour range, while high temperatures (above $225 \mathrm{~K}$ ) are shown in the yellow to red colour scale. There are no $\mathrm{ClO}$ measurements available for the period of 14-16 September 2005 (day 257 to 259) due to bad weather conditions (white bar).

ments available from 14-16 September 2005 and therefore these days are not considered in this study. At the beginning of the season (late August) the peak $\mathrm{ClO}$ mixing ratio occurs at around $22 \mathrm{~km}$. In early September the peak $\mathrm{ClO}$ mixing ratio shifts downwards, occurring at $20-21 \mathrm{~km}$. The maximum $\mathrm{ClO}$ mixing ratio increases from 1.2 parts per billion by volume (ppbv) to $2.3 \mathrm{ppbv}$ within the 28 day period. Between 17 and $23 \mathrm{~km}$ the temperatures reach their seasonal minimum $(<190 \mathrm{~K})$ during this time period, as also shown in Fig. 1. The atmospheric temperatures shown in Fig. 1 were extracted for the location of Scott Base from the National Centers for Environmental Prediction, NCEP (Kalnay et al., 1996) reanalyses using bilinear interpolation. 


\subsection{Model output - SLIMCAT 3-D CTM}

Output from the SLIMCAT 3-D off-line chemical transport model was used to provide estimates of the abundance of active chlorine $\left(\mathrm{ClO}_{\mathrm{x}}=\mathrm{ClO}+2 \times \mathrm{ClOOCl}\right)$, active bromine $\left(\mathrm{BrO}_{\mathrm{x}}=\mathrm{BrO}+\mathrm{BrCl}\right)$, and ozone over Antarctica. The model is described in detail in Chipperfield (1999, 2006). Briefly, SLIMCAT contains a detailed stratospheric chemistry scheme, including heterogeneous reactions of liquid and solid polar stratospheric clouds (PSCs). The model uses a limited number of small families in the chemistry module. Chlorine $(\mathrm{Cl}), \mathrm{ClO}$ and $\mathrm{ClOOCl}$ form a family and the partitioning between these species is found assuming instantaneous photochemical equilibrium. All other inorganic chlorine species (e.g. chlorine dioxide $(\mathrm{OClO})$, hypochlorous acid $(\mathrm{HOCl})$ etc.) are integrated separately. Similarly bromine $(\mathrm{Br})$ and bromine monoxide $(\mathrm{BrO})$ are solved as a family while all other inorganic bromine species are integrated separately (e.g. bromine monochloride $(\mathrm{BrCl})$ ).

For this study output was taken from the SLIMCAT 3D CTM. The run used here (for reference, run 509) has a resolution of $5.6^{\circ} \times 5.6^{\circ}$ with 32 levels from the surface to about $60 \mathrm{~km}$ and was started on 1 January 1977 . The run was forced using European Centre for Medium-Range Weather Forecasts (ECMWF) analyses (ERA-Interim after 1989). Daily profile output from the model run was stored for the location of Scott Base. The run included a source of bromine from very short-lived species, which contributed about 6 parts per trillion by volume (pptv) to total stratospheric inorganic bromine $\left(\mathrm{Br}_{\mathrm{y}}\right)$ in 2005 (Feng et al., 2007).

\section{Retrieval algorithm/optimal estimation}

An optimal estimation (OE) approach (Rodgers, 2000) is used to retrieve the kinetic parameters that optimize the agreement between the measured $\mathrm{ClO}$ profiles and profiles generated by the $\mathrm{OE}$ forward model. The quantities to be retrieved, $J / k_{\mathrm{f}}$ and $\mathrm{ClO}_{\mathrm{x}}$, from the $\mathrm{ClO}$ measurements $(\boldsymbol{Y})$ are represented, together with $K_{\text {eq }}$ and a dataset of 28 a priori $\mathrm{ClO}_{\mathrm{x}}$ profiles, by the state vector $(\boldsymbol{X})$. The resulting state vector has 563 elements, 3 kinetic parameters plus 28 days $\times 20$ altitudes for a priori $\mathrm{ClO}_{\mathrm{x}}$. Rather than working with $J / k_{\mathrm{f}}$ and $K_{\text {eq }}$ explicitly, they are specified as scalings (multiplicative factors) relative to the JPL06 recommendations. Hereafter, all quantities subscripted with scale refer to scaling with respect to JPL06. JPL06 kinetics are the point of reference for this study because these kinetic parameters are most commonly used in recently published studies of polar ozone photochemistry. In some cases, results are also compared with the more recent JPL09 recommendation. The JPL09 $K_{\text {eq }}$ value is $\sim 70 \%$ of the JPL06 value, while $J / k_{\mathrm{f}}$ for JPL09 shows essentially no difference from JPL06, except for a reduction of the uncertainties.
The relationship between the $\mathrm{ClO}$ measurements $(\boldsymbol{Y})$ and the state vector is described by a forward model $(\boldsymbol{F})$ that calculates $\mathrm{ClO}$ as a function of the state vector $\boldsymbol{X}$ and other parameters, $\boldsymbol{b}$, which include $\mathrm{BrO}_{\mathrm{x}}$, ozone, temperature, and pressure profiles:

$\boldsymbol{Y}=\boldsymbol{F}(\boldsymbol{X}, \boldsymbol{b})+\varepsilon$

where $\varepsilon$ is the measurement error. The error analysis for the Antarctic $\mathrm{ClO}$ measurements used in this study is described in depth in Solomon et al. (2000). The forward model $(\boldsymbol{F})$ is a photochemical steady state box model, based on polar ozone photochemistry and described in detail by Salawitch et al. (1993). The Salawitch et al. box model is used to calculate $\mathrm{ClO}$ at $30 \mathrm{~min}$ resolution for the 28 day period considered, for various specifications of the kinetic parameters, which are set to JPL06 values if not otherwise noted. Daily day minus night $\mathrm{ClO}$ profiles, hereafter modelled $\mathrm{ClO}(\hat{\boldsymbol{Y}})$, are calculated from the $30 \mathrm{~min}$ time resolution output of the box model using the same definition of day and night-time as for the analysis of the $\mathrm{ClO}$ measurements, to provide compatibility with the measured $\mathrm{ClO}$ profiles. For $\boldsymbol{b}$, the daily $\mathrm{BrO}_{\mathrm{x}}$ profiles were obtained from the SLIMCAT 3-D CTM (see Sect. 2.2). Because vertical ozone profiles from ozonesondes were not available for each day of the analysis period, ozone profiles were extracted from the SLIMCAT simulation. Linearly interpolated differences between measured and modelled ozone profiles were added to the SLIMCAT profiles so that they matched the ozonesonde measurements (taken from Hassler et al., 2008) on the days when measurements were available and provided best-estimates of ozone profiles on intervening days. Similar to the temperature profiles (Sect. 2.1), the pressure profiles for the analysis period were extracted from the NCEP reanalyses.

The inverse of Eq. (3) produces $\boldsymbol{X}$ as an output for a given $\boldsymbol{Y}$. There is an infinite set of such state vectors $\boldsymbol{X}$ that could form solutions to Eq. (3), reproducing the prescribed measurements. The retrieval problem is said to be under constrained, as there are more elements in the state vector than there are measurements. Given an a priori state vector $\left(\boldsymbol{X}_{a}\right)$, uncertainties on the elements of $\boldsymbol{X}_{a}$ (the covariance matrix $\mathbf{S}_{a}$ ) and the measurement error, the $\mathrm{OE}$ retrieves an optimal state vector $(\hat{\boldsymbol{X}})$ that minimizes the difference between measured and modelled $\mathrm{ClO} . \boldsymbol{X}_{a}$ constrains the $\mathrm{OE}$ algorithm. The iterative equation for the solution of the inverse of Eq. (3) is:

$$
\begin{aligned}
\hat{\boldsymbol{X}}_{i+1} & =\boldsymbol{X}_{a}+\left(\mathbf{S}_{a}^{-1}+\mathbf{K}_{i}^{T} \mathbf{S}_{e}^{-1} \mathbf{K}_{i}\right)^{-1} \mathbf{K}_{i}^{T} \mathbf{S}_{e}^{-1} \cdot\left[\boldsymbol{Y}-\boldsymbol{F}\left(\hat{\boldsymbol{X}}_{i}\right)\right. \\
& \left.+\mathbf{K}_{i}\left(\hat{\boldsymbol{X}}_{i}-\boldsymbol{X}_{a}\right)\right]
\end{aligned}
$$

where $\mathbf{K}$ is the weighting function matrix, with each element representing the partial derivative of the modelled $\mathrm{ClO}$ with respect to a state vector element; i.e. $\mathbf{K}_{i j}=d \boldsymbol{F}_{i}(\boldsymbol{X}) / d X_{j}$. As such, the weighting functions describe the sensitivity of the modelled $\mathrm{ClO}$ to variations in the state vector and were determined by consecutively perturbing each state vector quantity and recalculating $\mathrm{ClO}$ using the forward model. $\mathbf{S}_{e}$ in 


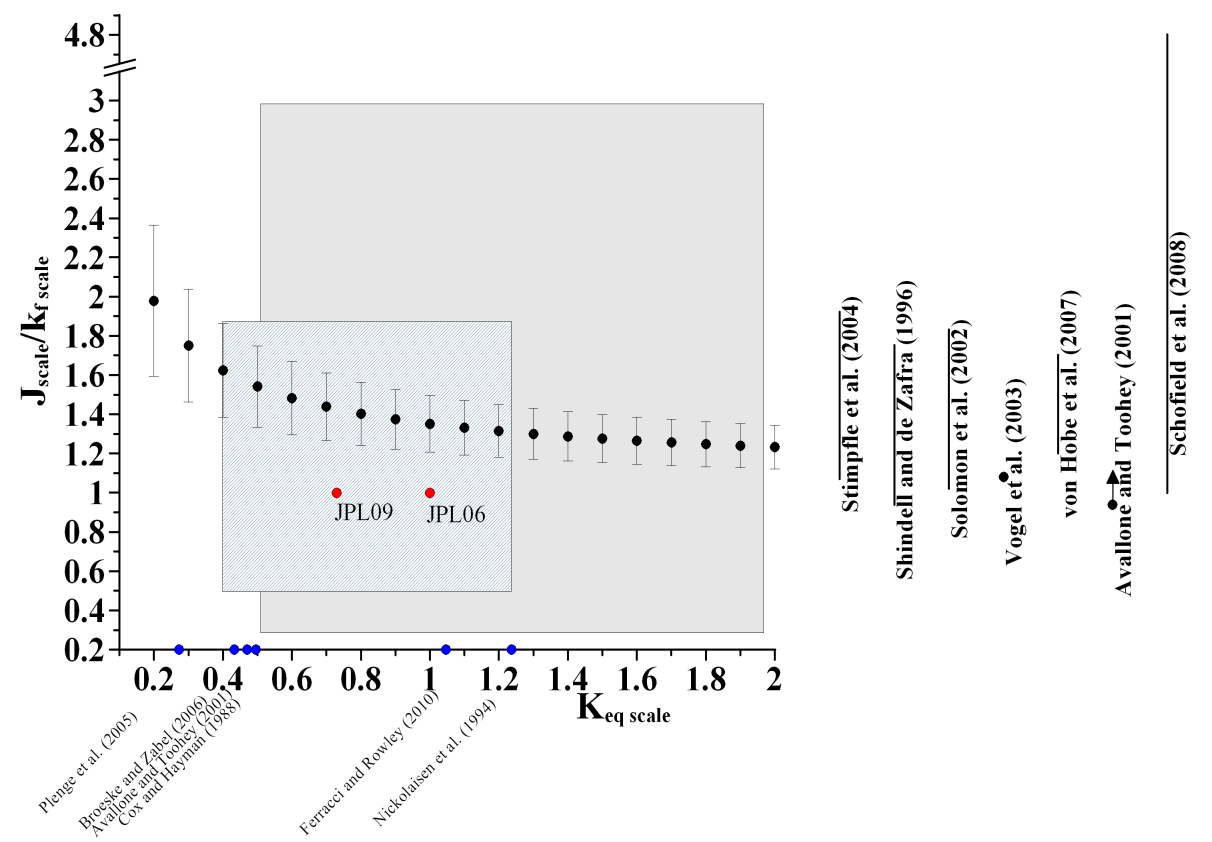

Fig. 2. The retrieved scale factors and $1 \sigma$ uncertainties for $J / k_{\mathrm{f}}$ and $K_{\text {eq }}$ from all OE runs. Vertical bars along the y-Axis: Results from earlier studies for $J_{\text {scale }} / k_{\mathrm{f}}$ scale at $190 \mathrm{~K}$. Blue symbols along the X-axis: $K_{\text {eq scale }}$ relative to JPL06 determined from earlier studies $(190<T<210 \mathrm{~K})$. Light grey area: JPL06 uncertainty range on $K_{\text {eq }}$ and $J / k_{\mathrm{f}}$. Smaller rectangular hatched area towards the bottom left: JPL09 uncertainty range on $K_{\text {eq }}$ and $J / k_{\mathrm{f}}$ (for more details see text).

Eq. (4) is the covariance matrix of the measurement errors (Fig. 1b), constructed by placing the $\mathrm{ClO}$ measurement errors along the diagonal, and set to zero everywhere else. $\boldsymbol{X}_{a}$ was constructed by inserting values for $k_{\mathrm{f}}$ scale,$K_{\text {eq scale }}$ and

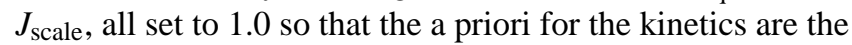
JPL06 recommendations. A set of 28 a priori $\mathrm{ClO}_{x}$ profiles, corresponding to each day of measurement, is provided as a required input to the forward model.

The uncertainties on the elements of $\boldsymbol{X}_{a}$ are expressed along the diagonal of a covariance matrix $\mathbf{S}_{a}$, which is elsewhere set to zero. Selection of the $\mathbf{S}_{a}$ settings requires some subjective judgement, noting that if excessively small values are chosen, the retrieval will be constrained too tightly. In this case the retrieval will make little use of the information provided by the measurements and will differ little from the prescribed a priori $\boldsymbol{X}_{a}$. On the other hand, if excessively large values for $\mathbf{S}_{a}$ are chosen, this results in an unrealistic retrieval where the measurement noise is interpreted as information. Here the $\mathbf{S}_{a}$ values for $k_{\mathrm{f} \text { scale }}, J_{\text {scale }}$ and the a priori $\mathrm{ClO}_{\mathrm{x}}$ profiles were numerically determined as described in Schofield et al. (2004) and are set to $\sigma_{k_{\mathrm{f}} \text { scale }}=0.043$ and $\sigma_{J_{\text {scale }}}=0.173$. The $\mathbf{S}_{a}$ values for the a priori $\mathrm{ClO}_{\mathrm{x}}$ were set to $20 \%$ of the daily maximum $\mathrm{ClO}_{\mathrm{x}}$ value, individually for each day, also as done by Schofield et al. (2004).

During day-time the partitioning of $\mathrm{ClO}$ and its dimer is governed by $J / k_{\mathrm{f}}$ (see Eq. 1). $K_{\text {eq }}$ becomes important primarily for the night-time partitioning of $\mathrm{ClO}_{\mathrm{x}}$. Because the night-time spectrum was subtracted from the day- time spectrum to obtain a daily measured $\mathrm{ClO}$ profile, the $\mathrm{ClO}$ measurements mostly give information on $J / k_{\mathrm{f}}$, and only very little information on these parameters individually. Furthermore, the measurements are only weakly sensitive to $K_{\text {eq }}$. Therefore, with the OE approach we retrieve $J_{\text {scale }} / k_{\text {f scale }}$ and make no attempt to retrieve $K_{\text {eq }}$. Rather, to test the sensitivity of our results to the choice of $K_{\text {eq scale }}$, OE is done 19 times, varying $K_{\text {eq scale }}$ from $0.2 \times K_{\text {eq JPL06 }}$ to $2.0 \times K_{\text {eq JPL06 }}$ in steps of $0.1 \times K_{\text {eq JPL06 }}$.

Complementary to the $\mathrm{OE}$ approach, a second method was used to derive the kinetic parameters of the $\mathrm{ClO}$ dimer cycle. In this approach the full parameter space was explored by varying the values of the $J, k_{\mathrm{f}}$ and $K_{\text {eq scale factors within }}$ physically plausible ranges. Furthermore, to estimate the dependence of the retrieved kinetic parameters on changes in the prescribed $\mathrm{ClO}_{\mathrm{x}}$ profile, the $\mathrm{ClO}_{\mathrm{x}}$ profile was scaled between 0.5 and 1.0 times the a priori $\mathrm{ClO}_{\mathrm{x}}$ profile used in the $\mathrm{OE}$ approach, in steps of 0.1 times the a priori $\mathrm{ClO}_{\mathrm{x}}$ profile (scalings above 1.0 were not used since this resulted in $\mathrm{ClO}_{\mathrm{x}}$ occasionally exceeding the total stratospheric inorganic chlorine $\left(\mathrm{Cl}_{\mathrm{y}}\right)$ loading). The photochemical model described above in Sect. 3 was also used here, with the same input variables (i.e. $\mathrm{BrO}_{\mathrm{x}}$, ozone) to calculate day minus night profiles of $\mathrm{ClO}$ (again, to be compatible with the $\mathrm{ClO}$ measurements). The kinetic values that give the smallest difference between the modelled and the measured $\mathrm{ClO}$ are compared to the results from the $\mathrm{OE}$ and previous publications. 


\section{Results}

\subsection{Retrieved kinetic parameters from optimal estimation}

The measurements were well described by the forward model for each OE run, with root mean square (RMS) differences between measured and modelled $\mathrm{ClO}$ ranging from 0.063 to $0.066 \mathrm{ppbv}$, which is smaller than the maximum error of the $\mathrm{ClO}$ measurements $(0.11 \mathrm{ppbv})$. The results from the retrievals performed as outlined in Sect. 3, expressed as scale factors relative to the kinetic parameters recommended by JPL06, are shown together with $1 \sigma$ uncertainties in Fig. 2. In addition to prescribing $J$ and $k_{\mathrm{f}}$ from JPL06 as a priori in the forward model, JPL06 kinetics were used for all other chemistry in the forward model. The derived RMS values for the $19 \mathrm{OE}$ runs do not vary much (only by $\sim 5 \%$ ), but the change in the retrieved $J / k_{\mathrm{f}}$ ratios over the prescribed $K_{\text {eq }}$ range ( 0.2 to 2.0$)$ is significant. The ratio retrieved by prescribing $K_{\text {eq scale }}=2.0$ is about a factor of 1.6 smaller than the $J_{\text {scale }} / k_{\mathrm{f}}$ scale ratio retrieved for the smallest $K_{\text {eq scale }}=0.2$ used in this study. Tests using JPL09 kinetics showed only very slightly $(\sim 2 \%)$ larger values for the $J_{\text {scale }} / k_{\mathrm{f}}$ scale ratio, which is an insignificant difference given other sources of uncertainty. A $J_{\text {scale }} / k_{\mathrm{f}}$ scale value of 1.0 refers to the JPL06 recommendations, where the photolysis frequency of the dimer $(J)$ is calculated using the absorption cross-sections recommended JPL06. $J_{\text {scale }} / k_{\text {f scale }}$ values relative to JPL06 determined in earlier studies are indicated with vertical bars along the Y-axis in Fig. 2. The salient features of Fig. 2 and their causes are:

- Negative slope: When prescribing $K_{\mathrm{eq}}$, according to Eq. (2), the night-time partitioning between $\mathrm{ClO}$ and its dimer and therefore night-time $\mathrm{ClO}$ concentrations are prescribed in the forward model, with larger $K_{\text {eq }}$ meaning lower night-time $\mathrm{ClO}$ concentrations. As a result, depending on the choice of $K_{\text {eq }}$, different modelled night-time $\mathrm{ClO}$ concentrations were subtracted from the modelled day-time $\mathrm{ClO}$ concentrations to calculate the day minus night profile, which is compared to the $\mathrm{ClO}$ observations. When trying to minimize the differences between modelled and observed profiles, optimal estimation compensates for the differences in the modelled day minus night $\mathrm{ClO}$ profiles resulting from different choices of $K_{\text {eq scale }}$ by varying $J_{\text {scale }} / k_{\mathrm{f}}$ scale. Therefore, optimal estimation increases $J_{\text {scale }} / k_{\mathrm{f}}$ scale for smaller $K_{\text {eq scale }}$, resulting in more $\mathrm{ClO}$ during the day (see $\mathrm{Re}-$ actions R1, R2).

- Asymptotic behaviour of $J_{\text {scale }} / k_{\mathrm{f}}$ scale at high $K_{\text {eq scale }}$ : At $K_{\text {eq }}$ values greater than $1.2 \times K_{\text {eq JPL06 }}$ night-time $\mathrm{ClO}$ concentrations become almost negligible so that the modelled day minus night $\mathrm{ClO}$ profiles are rather similar and the retrieved optimal $J_{\text {scale }} / k_{\mathrm{f}}$ scale values do not vary significantly.
Due to the lack of $\mathrm{ClO}$ night-time measurements it is not possible to determine the exact $K_{\text {eq }}$ that corresponds to the Antarctic $\mathrm{ClO}$ measurements made during the analysis period. Therefore, in this study, a single value for $J / k_{\mathrm{f}}$ that best reproduces the measurements also cannot be determined, but rather a range of $J / k_{\mathrm{f}}$ values is provided depending on the choice of $K_{\text {eq }}$.

The $J_{\text {scale }} / k_{\mathrm{f}}$ scale ratio of 1.39 interpolated to the $K_{\text {eq }}$ prescribed by Solomon et al. $(2000)\left(K_{\text {eq scale }}=0.86\right)$ agrees very well with their $J_{\text {scale }} / k_{\mathrm{f}}$ scale ratio (see Fig. 2). Solomon et al. used measurements from the same $\mathrm{ClO}$ microwave radiometer at the same site. The measurements they used were taken from a different period (late winter/early spring 19962000) when when stratospheric temperatures were, on average, $4 \mathrm{~K}$ lower than in the analysis period our study focuses on, i.e. the period from 21 August to 20 September 2005 (Fig. 1c). The formation rate of the dimer and the equilibrium constant are both known to be temperature dependent. A decrease in temperature leads to an increase in the dimer formation rate $k_{\mathrm{f}}$, which in turn leads to a decrease in the $J / k_{\mathrm{f}}$ ratio. However, Solomon et al. used the JPL97 functional form for the temperature dependence of $k_{\mathrm{f}}$, which is different from the JPL06 expression used here. The difference between JPL97 and JPL06 then partially offsets the effect of the temperature difference between the two studies.

The retrieved $J_{\text {scale }} / k_{\mathrm{f}}$ scale ratios from all $19 \mathrm{OE}$ runs lie within the lower half of the large uncertainty range given by JPL06, within the upper half of the smaller uncertainty range given by JPL09, and with most of the $J_{\text {scale }} / k_{\mathrm{f}}$ scale ratios determined in previous studies (Fig. 2). The results suggest that to explain the $\mathrm{ClO}$ measurements measurements from Scott Base, Antarctica, made from August to September in $2005, J / k_{\mathrm{f}}$ is unlikely to be smaller than the JPL06/09 recommendations. This result would exclude the lower uncertainty limit on $J / k_{\mathrm{f}}$ for both JPL06 and JPL09.

The best fit to the $\mathrm{ClO}$ measurements, i.e. the smallest RMS of the difference between modelled and measured $\mathrm{ClO}$, is obtained at $K_{\text {eq scale }}=2.0$. In this case $J_{\text {scale }} / k_{\mathrm{f}}$ scale is $1.23 \pm 0.11$. In contrast to previous studies, our results suggest that to best represent the $\mathrm{ClO}$ measurements, $K_{\text {eq scale }}$ must lie towards the upper end of the prescribed range $(0.2$ to 2.0), in agreement with the recent laboratory study of Ferracci and Rowley (2010). However, the derived $K_{\text {eq }}$ values in Ferracci and Rowley were obtained at higher temperatures than in this study. To explain the $\mathrm{ClO}$ measurements, the results presented in this study (Fig. 2) do not preclude higher $K_{\text {eq }}$ values than currently recommended. That said, the decrease in RMS from $K_{\text {eq scale }}=0.2$ to 2.0 is small ( $5 \%$ ), suggesting that $K_{\text {eq }}$ is not well constrained by the measurements of $\mathrm{ClO}$ and therefore a robust evaluation of $K_{\mathrm{eq}}$ is difficult (see Sect. 3).

The RMS values obtained from the $\mathrm{OE}$ are elevated as a result of the inclusion of two days of measurements. Between 7 September (day 250) and 8 September 2005 (day 251), $\mathrm{ClO}$ dropped from $\sim 2.2 \mathrm{ppbv}$ to $\sim 0.8 \mathrm{ppbv}$ before increasing 
back to $\sim 2$ ppbv two days later (see Fig. 1a). The suppressed values of $\mathrm{ClO}$ over this two day period are caused by dynamical variability of the polar vortex. While SLIMCAT shows some reduction in $\mathrm{ClO}_{\mathrm{x}}$ over this period, the reduction is not commensurate with the observed reduction in $\mathrm{ClO}$, as is apparent in the disagreement between measured and SLIMCAT modelled $\mathrm{ClO}$ profiles on these days (not shown). With the given resolution of the SLIMCAT run (see Sect. 2.2), the model cannot capture the observed strong gradients at the edge of the vortex. Therefore, the a priori $\mathrm{ClO}_{\mathrm{x}}$ profiles provided by SLIMCAT are too high on those two days. The value of $J_{\text {scale }} / k_{\mathrm{f}}$ scale is determined by the partitioning of $\mathrm{ClO}$ and $\mathrm{ClOOCl}$ on all days and is not determined separately for every day. The amount of $\mathrm{ClO}_{\mathrm{x}}$, on the other hand, can vary for every day independently within the given uncertainty range, which is determined by the set up of the a priori uncertainty $\left(\mathbf{S}_{a}\right)$. The selection of the magnitude of the elements of $\mathbf{S}_{a}$ determines the freedom of the OE, i.e. how well constrained is the OE. The selected uncertainties on the a priori $\mathrm{ClO}_{\mathrm{x}}$ profile (see Sect. 3) are likely to be too small for the two days and therefore the OE is constrained too tightly. The retrieval does not have enough freedom to modulate $\mathrm{ClO}_{\mathrm{x}}$, for the given $J_{\text {scale }} / k_{\mathrm{f}}$ scale, to reproduce the measurements. The combination of $J_{\text {scale }} / k_{\mathrm{f}}$ scale with a higher amount of $\mathrm{ClO}_{\mathrm{x}}$ leads to more $\mathrm{ClO}$ than observed and thereby contributes to the higher RMS values. While excluding the two days from the analysis reduces the RMS such that it is smaller than the measurement uncertainty at every altitude level, the retrieved $J_{\text {scale }} / k_{\mathrm{f}}$ scale increases slightly, from $1.35 \pm 0.14 \times\left(J / k_{\mathrm{f}}\right) \mathrm{JPL} 06$ (all data points) to $1.44 \pm 0.18 \times\left(J / k_{\mathrm{f}}\right)_{\mathrm{JPL} 06}(8$ and 9 September excluded), if $K_{\text {eq }}=K_{\text {eq JPL06 }}$. The difference between the two calculations is not statistically significant. This result shows the sensitivity of the applied OE method to the a priori $\mathrm{ClO}_{\mathrm{x}}$ information. Since there is no valid scientific reason for excluding these two days in question, and because they have only a small effect on the retrieved value of $J_{\text {scale }} / k_{\mathrm{f}}$ scale , these two days were retained in the prior results of this section as well as in the OE analyses discussed further in Sect. 5.

\subsection{Exploring the full parameter space}

In contrast to the $\mathrm{OE}$ approach, the $k_{\mathrm{f} \text { scale }}, J_{\text {scale, }}$, and $K_{\text {eq scale }}$ parameter space was explored to derive the optimal $\mathrm{ClO}$ dimer cycle kinetic parameters required to explain the measured ClO. The study by Santee et al. (2010) reported that SLIMCAT overestimates the $\mathrm{ClO}_{\mathrm{x}}$ concentration by about $25 \%$ in the Antarctic. Since the $\mathrm{ClO}_{x}$ values obtained from SLIMCAT may be uncertain, sensitivity to $\mathrm{ClO}_{x}$ was also explored by scaling $\mathrm{ClO}_{\mathrm{x}}$ from 0.5 to 1.0 . Scalings above 1.0 were not considered since this resulted in $\mathrm{ClO}_{x}$ occasionally exceeding $\mathrm{Cl}_{\mathrm{y}} . J_{\text {scale }}$ was varied between 0.1 and 2.5 , while $k_{\mathrm{f} \text { scale }}$ was varied between 0.4 and 1.6. An upper bound of $K_{\text {eq scale }}=1.6$ was used since JPL09 and most other studies (with the notable exceptions of Nickolaisen et al.
(1994); Ferracci and Rowley (2010)) suggest $K_{\text {eq scale }} \leq 0.7$. Within this space, the kinetic values that give the smallest RMS of the difference between modelled and measured $\mathrm{ClO}$ were determined.

The results from exploring the full parameter space would be best represented in a 4-D plot. However, a 4-D plot is far too complex and impossible to show on 2-D paper and for the purpose of this study it is sufficient and necessary to display the results in two dimensions. From the number of available 2-D plots (i.e. 90 figures could be drawn showing the evolution of $J$ and $k_{\mathrm{f}}$ with changing $K_{\mathrm{eq}}$ and $\mathrm{ClO}_{\mathrm{x}}$ ), 15 plots were generated where the minimum RMS values for every combination of $J$ and $k_{\mathrm{f}}$ corresponding to one of the $6 \mathrm{ClO}_{\mathrm{x}}$ scalings were determined for every $K_{\text {eq }}$ separately. The minimum RMS values (from the $6 \mathrm{ClO}_{\mathrm{x}}$ scalings) are shown for each combination of $J_{\text {scale }}$ and $k_{\mathrm{f} \text { scale }}$ and for a selected number of $K_{\text {eq scale }}\left(K_{\text {eq }}=0.4,0.8,1.2\right.$ and 1.6) in Fig. 3. In all cases the lowest RMS values are found for $\mathrm{ClO}_{\mathrm{x} \text { scale }}=1.0$ (unshaded regions in Fig. 3) and the absolute minimum RMS for the highest $K_{\text {eq scale }}$ (Fig. 3d), in agreement with the results obtained from OE. While lower RMS values might have been found for $\mathrm{ClO}_{\mathrm{x}}$ scale $>1.0$, this would be physically unrealistic for the reasons detailed above. The calculated minimum RMS in the $J_{\text {scale }}-k_{\text {f scale }}$ plane, for each $K_{\text {eq scale, }}$, shows little dependence on $K_{\text {eq scale }}$, confirming again that our measurements do not provide a strong constraint on $K_{\text {eq }}$.

The RMS values define a "valley" of minima in each $J_{\text {scale }}-k_{\mathrm{f}}$ scale plane. According to Eq. (1) a given $\mathrm{ClO}_{\mathrm{x}}$ and observed $\mathrm{ClO}$ concentration constrain the $\left[\mathrm{ClO}^{2} /[\mathrm{ClOOCl}]\right.$ ratio and $J_{\text {scale }}$ and $k_{\mathrm{f}}$ scale must essentially increase or decrease together. This explains the orientation of the valley of minimum RMS values seen in Fig. 3. The angle that this valley makes with the $\mathrm{X}$-axis decreases slightly with increasing $K_{\text {eq scale, }}$ indicating a decrease in $J_{\text {scale }} / k_{\mathrm{f}}$ scale with increasing $K_{\text {eq scale, }}$ which is in agreement with the results from the $19 \mathrm{OE}$ runs described in Sect. 4.1. The ClO measurements mostly give information on $J / k_{\mathrm{f}}$ and contain very little information on these parameters individually (see Sect. 3). Therefore, the $J / k_{\mathrm{f}}$ ratio that best explains the $\mathrm{ClO}$ measurements can be derived from the orientation of the valley with an uncertainty constrained by the width of

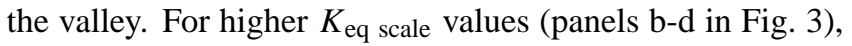
the orientation of the valley suggests a $J_{\text {scale }} / k_{\text {f scale }}$ ratio smaller than 1, which would disagree with the OE result. However, taking the absolute minimum RMS in each panel leads to $J_{\text {scale }} / k_{\mathrm{f} \text { scale }}$ of $\sim 1.66$ for $K_{\text {eq scale }}=0.4,0.8$, and 1.2 , and $J_{\text {scale }} / k_{\text {f scale }}=1.25$ for $K_{\text {eq scale }}=1.6$ (at the absolute minimum RMS). This independently derived result is in good agreement with the retrieved ratios of $1.62 \pm 0.24$, $1.40 \pm 0.16,1.32 \pm 0.13$ and $1.27 \pm 0.28$ from OE, for $K_{\text {eq scale }}$ prescribed at $0.4,0.8,1.2$, and 1.6, respectively. However, the resulting valley of RMS minima using $J_{\text {scale }} / k_{\mathrm{f}}$ scale ratios of 1.66 and 1.25 would require $\mathrm{ClO}_{\mathrm{x}}$ scale values smaller than 1. 

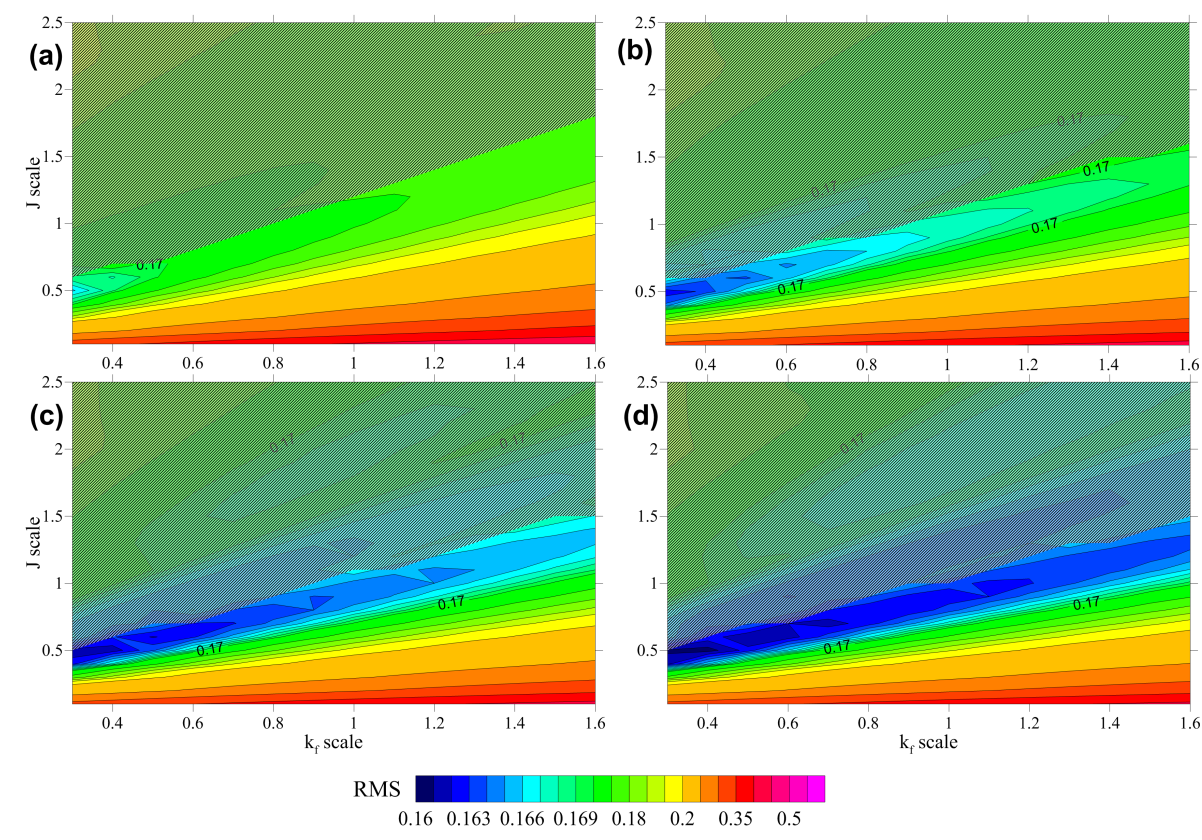

Fig. 3. Scale factors for $J$ and $k_{\mathrm{f}}$ with the corresponding RMS minimum derived from exploring the parameter space by varying $k_{\mathrm{f}}$ scale,

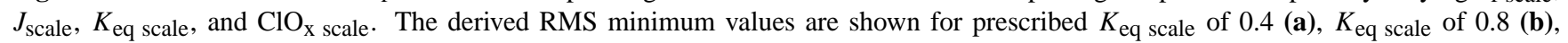
$K_{\text {eq scale }}$ of 1.2 (c), and $K_{\text {eq scale }}$ of 1.6 (d). The blue colour scale indicates the smallest RMS values (below 0.168), while RMS values greater than 0.2 are shown in orange/red colours. The dark, hatched area towards the top left of the panels shows the RMS values where the $\mathrm{ClO}_{\mathrm{x}}$ scale factor was not equal to 1 (for details see text).

The RMS values obtained from exploring the whole parameter space are more than twice as large as those resulting from OE. Therefore, the results from the OE approach lead to a better fit to the $\mathrm{ClO}$ measurements than the results from exploring the whole parameter space. Contrary to the $\mathrm{OE}$ approach, the sampling of the whole parameter space does not readily permit changing the $\mathrm{ClO}_{\mathrm{x}}$ value from day to day or from one altitude level to another. The parameter space exploration scales $\mathrm{ClO}_{\mathrm{x}}$ values on all days and at all levels equally. This most likely explains the higher RMS values for the parameter space exploration.

\section{Discussion}

The retrieved kinetic parameters from the optimal estimation runs (Sect. 4.1) and the results derived by exploring the whole parameter space (Sect. 4.2) agree very well within the given uncertainties of optimal estimation. The retrieved $J_{\text {scale }} / k_{\mathrm{f}}$ scale ratios for various $K_{\text {eq scale }}$ reflect a range of combinations of $J, k_{\mathrm{f}}$, and $K_{\text {eq }}$ values which are consistent with the Antarctic $\mathrm{ClO}$ measurements, i.e. there is not only one optimal combination of $J, k_{\mathrm{f}}$, and $K_{\text {eq }}$. The possible combinations of kinetic parameters derived in previous field and laboratory studies and values recommended by JPL that can be used to explain the $\mathrm{ClO}$ observations are discussed below.
In agreement with Stimpfle et al. (2004), using a $J_{\text {JPL06 }}$ value together with a smaller $k_{\mathrm{f}}$ value relative to JPL06 (Trolier et al., 1990) was found to reproduce the ClO measurements. Furthermore, Stimpfle et al. concluded that the laboratory measurement of $K_{\text {eq }}$ from Cox and Hayman (1988) agrees best with $\mathrm{ClO}$ and $\mathrm{ClOOCl}$ observations $(190 \mathrm{~K}<T<200 \mathrm{~K})$. Prescribing the $K_{\text {eq }}$ value derived by Cox and Hayman results in a $J_{\text {scale }} / k_{\mathrm{f}}$ scale ratio of $1.54 \pm 0.21$. This ratio would also include such a combination of $J$ and $k_{\mathrm{f}}$ as mentioned above, i.e. $J_{\mathrm{JPL} 06}$ and $k_{\mathrm{f}}$ Trolier, to explain the $\mathrm{ClO}$ measurements.

$K_{\text {eq }}$ determined by Plenge et al. (2005) would lead to a $J / k_{\mathrm{f}}$ ratio of $1.75 \pm 0.51 \times\left(J / k_{\mathrm{f}}\right)_{\mathrm{JPL}} 06$. This result suggests that the photolysis frequency of the dimer is higher than currently recommended and lies within the range of 1.25 to $2.25 \times J_{\mathrm{JPL} 06}$ if $k_{\mathrm{f} \mathrm{JPL} 06}$ is correct. If the photolysis frequency determined by JPL06 is used, then $k_{\mathrm{f}}$ has to be smaller than currently recommended (between $45 \%$ and $80 \%$ of $k_{\mathrm{f}}$ JPL06). These results suggest that using $K_{\text {eq Plenge }}$ would lead to higher modelled $\mathrm{ClO}$ abundances than using the current JPL recommendations.

If $K_{\text {eq }}$ is fixed to JPL06 then our results indicate that $J / k_{\mathrm{f}}=1.35 \pm 0.14 \times\left(J / k_{\mathrm{f}}\right)_{\mathrm{JPL} 06}$. Using $J_{\mathrm{JPL} 06}$ requires a smaller $k_{\mathrm{f}}$ value than currently recommended and our results show that $k_{\mathrm{f}}$ must lie in the range of 0.6 to $0.95 \times k_{\mathrm{f}}$ JPL06 to explain the measurements. Therefore, the results presented by Bloss et al. (2001) and Trolier et al. (1990) for $k_{\mathrm{f}}$ together 
with the JPL06 recommendation for $J$ and $K_{\text {eq }}$ are consistent with the $\mathrm{ClO}$ measurements used in this study.

Using a combination of $K_{\text {eq scale }}=0.2$ (which is at the lowest end of the $K_{\text {eq scale }}$ range explored in this study) and a $J$ value obtained from the Burkholder et al. (1990) crosssections, which agrees with the value of $J$ found using crosssections of the more recent study by Papanastasiou et al. (2009), requires a $k_{\mathrm{f}}$ scale value greater than 0.55 to be consistent with the $\mathrm{ClO}$ measurements. An increase in both $J$ and $k_{\mathrm{f}}$ relative to the JPL06 recommendation would lead to an increase in the calculated ozone loss by the $\mathrm{ClO}$ dimer cycle, because chlorine is cycled more quickly through the different steps of the catalytic cycle.

Night-time $\mathrm{ClO}$ measurements were used in the past to determine the equilibrium constant (e.g., Stimpfle et al., 2004; von Hobe et al., 2005; Santee et al., 2010). Given these studies and studies performed in the laboratory (e.g., Plenge et al., 2005), it is more likely that $K_{\text {eq scale lies between } 0.27}$ and 0.5 than being far greater than recommended by JPL06. Furthermore, the study by von Hobe et al. (2007) found that their stratospheric $\mathrm{ClO}$ observations were described well using a similar scaling for $K_{\text {eq }}$. The JPL09 recommendation also provides a smaller $K_{\text {eq }}$ value $\left(0.7 \times K_{\text {eq JPL06 }}\right)$ than previously recommended in JPL06. The range of $K_{\text {eq scale }}$ between 0.27 and 0.7 , together with the results from our $\mathrm{OE}$ approach, suggest that $J / k_{\mathrm{f}}$ values lie between $1.75 \pm 0.29$ and $1.44 \pm 0.17 \times\left(J / k_{\mathrm{f}}\right)_{\mathrm{JPL} 06}$. The analyses presented above show that using these combinations of the kinetic parameters would include $J$ and $k_{\mathrm{f}}$ values which are consistent with the JPL06 recommendations within the given uncertainty ranges of $J_{\mathrm{JPL} 06}$ and $k_{\mathrm{f}} \mathrm{JPL} 06$. Furthermore, this result would preclude $J$ values smaller than currently recommended (e.g., Pope et al., 2007) and would exclude the lower uncertainty range on the $J_{\mathrm{JPL} 06}$ value.

\section{Summary and conclusions}

Two methods, both using ground-based $\mathrm{ClO}$ measurements made during the period from 21 August to 20 September 2005 in Antarctica, to derive the key kinetic parameters that govern the day-time partitioning between $\mathrm{ClO}$ and $\mathrm{ClOOCl}$ were presented. The day-time $\mathrm{ClO}$ profiles were retrieved from day minus night spectra, where the measured night-time spectrum was subtracted from the measured day-time spectrum. As a result, the Antarctic $\mathrm{ClO}$ measurements mostly contain information about $J / k_{\mathrm{f}}$, where $J$ is the photolysis frequency and $k_{\mathrm{f}}$ the $\mathrm{ClO}$ dimer formation rate. This study aimed to deduce the best $J / k_{\mathrm{f}}$ ratio, representing the optimal fit to the measurements. Rather than working with the kinetic parameters explicitly, they are specified as scalings relative to JPL06 recommendations. The retrieved $J_{\text {scale }} / k_{\mathrm{f}}$ scale ratio then provides a range of combinations of $J_{\text {scale }}$ and $k_{\mathrm{f}}$ scale that are consistent with the $\mathrm{ClO}$ measurements. Due to the day minus night subtraction performed in obtaining the mea- sured $\mathrm{ClO}$ profile, no attempt was made to retrieve the equilibrium constant $K_{\text {eq }}$. Rather, to allow a sensitivity study of the derived $J_{\text {scale }} / k_{\mathrm{f}}$ scale ratios to a choice of $K_{\text {eq }}, K_{\text {eq }}$ was varied within physically plausible limits.

First, optimal estimation (OE) was applied to retrieve the optimal $J / k_{\mathrm{f}}$ ratio that corresponds to the minimum of the differences between measured and calculated $\mathrm{ClO}$ concentrations. Nineteen optimal estimation runs were performed where $K_{\text {eq }}$ was prescribed to values between 0.2 and $2.0 \times K_{\text {eq JPL06. }}$. To confirm the results from the optimal estimation, and to test how much more information can be derived when sampling the whole parameter space, one run was performed where the kinetic parameters and the $\mathrm{ClO}_{\mathrm{x}}$ profiles were varied within physically plausible ranges to determine the combination of these parameters that minimizes the sum of the squares of the differences between the modelled and the measured $\mathrm{ClO}$ profiles.

The results presented above confirm, as also shown in Schofield et al. (2008), that OE is a reliable method for investigating the kinetics of the $\mathrm{ClO}$ dimer cycle. The results derived by exploring the whole parameter space agree with the retrieved kinetics from the OE runs. OE has the advantage that it is much faster than sampling the parameter space and provides quantitative estimates of the uncertainties on the derived parameters. Furthermore, the $\mathrm{OE}$ retrieves a quantitative estimate of the daily $\mathrm{ClO}_{\mathrm{x}}$ abundances required to explain the observed $\mathrm{ClO}$ concentrations. Exploring the whole 4-D space is computationally expensive and changing $\mathrm{ClO}_{\mathrm{x}}$ individually for every day would make it even more so. OE gives one set of parameters and, as shown above, these results provide a reliable fit to the measurements.

The results presented above indicate that the retrieved $J_{\text {scale }} / k_{\mathrm{f} \text { scale }}$ ratios from all $19 \mathrm{OE}$ runs agree with most values reported in previous studies and lie within the lower half of the large uncertainty range reported by JPL06. The recently updated JPL09 recommendation reports a much smaller uncertainty range on the $\mathrm{ClOOCl}$ absorption crosssections than JPL06. As a result, the uncertainty range on the $\mathrm{ClOOCl}$ photolysis frequency $(J)$ is reduced, which in turn places tighter constraints on the $J / k_{\mathrm{f}}$ ratio than given by JPL 06 . The retrieved $J_{\text {scale }} / k_{\mathrm{f}}$ scale for prescribed $K_{\text {eq }}$ values of 0.4 to 1.2 times JPL06, which correspond to 0.6 to 1.7 times JPL09, lies within the upper part of the uncertainty range given for $J / k_{\mathrm{f}}$ by JPL09.

The 2005 ground-based microwave $\mathrm{ClO}$ measurements made over Scott Base, Antarctica, can be explained using the JPL06 recommendations of $J, k_{\mathrm{f}}$, and $K_{\mathrm{eq}}$ with the given range of uncertainties (Fig. 2). Our study suggests a greater value of $J / k_{\mathrm{f}}$ than the JPL06 value (i.e., either faster photolysis of $\mathrm{ClOOCl}$, slower rate of formation of $\mathrm{ClOOCl}$ by the self reaction of $\mathrm{ClO}$, or some combination of these two perturbations), but the retrieved values lie within the rather large uncertainty limits of the JPL recommendations.

The best fit to the $\mathrm{ClO}$ measurements is achieved by using

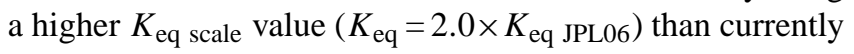


recommended by JPL06/09, leading to a $J_{\text {scale }} / k_{\text {f scale }}$ value of $1.23 \pm 0.11 \times\left(J / k_{\mathrm{f}}\right)_{\mathrm{JPL}} 06$. While this finding agrees with the higher $K_{\text {eq }}$ values found by Ferracci and Rowley (2010), we caution that our retrieved values of $K_{\text {eq }}$ are not well constrained by the measurements of $\mathrm{ClO}$.

$K_{\text {eq }}$ governs the partitioning of $\mathrm{ClO}$ and its dimer primarily during the night. Therefore, $\mathrm{ClO}$ day-time measurements are only weakly sensitive to $K_{\text {eq }}$, which likely explains the small change in the RMS values over the relatively large prescribed range of $K_{\text {eq scale }}(0.2$ to 2.0$)$. Night-time measurements of $\mathrm{ClO}$ are required to determine a reliable value of $K_{\text {eq. }}$. Although this study does not provide a tight constraint on $K_{\text {eq }}$, the retrieved $J / k_{\mathrm{f}}$ obtained here is robust against the uncertainty in $K_{\text {eq }}$. However using both day-time and nighttime measurements would provide a means to estimate $K_{\text {eq }}$ and an estimate of $J / k_{\mathrm{f}}$ that would be largely independent of $K_{\text {eq. }}$.

The results presented above are in basic agreement with earlier field and laboratory studies. In this study, a single value for $J / k_{\mathrm{f}}$ could not be determined due to the lack of night-time $\mathrm{ClO}$ observations, rather a range of $J / k_{\mathrm{f}}$ ratios was provided depending on what is assumed for $K_{\text {eq. }}$. This highlights the need for a greater number of night-time $\mathrm{ClO}$ measurements under stratospheric conditions to derive independent information on the kinetic parameters governing the effectiveness of the $\mathrm{ClO}$ dimer cycle.

Acknowledgements. We thank Alan Parrish for his significant input in both the development of the $\mathrm{ClO}$ microwave radiometer and the initiation of the ground-based measurement program. We thank S. Wood, M. Kotkamp and Antarctica New Zealand for their help in maintaining the $\mathrm{ClO}$ microwave radiometer and their help in obtaining the $\mathrm{ClO}$ measurements. The ground-based measurement program is funded by NASA, grant NNX09AF40G. R. Schofield was funded by European Union (EU) project WaVES (MIF1-CT-2006-039646). The participation of R. Salawitch and T. Canty was supported by the NASA Aura and ACMAP programs. The SLIMCAT modelling work at Leeds was supported by NERC NCAS and the EU GEOMON project. S. Kremser thanks the German Academic Exchange Service (DAAD) for their support throughout the Doktorandenstipendium, which allowed this work to be conducted. We would like to thank Marc von Hobe and one anonymous reviewer for valuable comments and suggestions that contributed to a much improved manuscript following initial submission.

Edited by: W. Lahoz

\section{References}

Atkinson, R., Baulch, D. L., Cox, R. A., Crowley, J. N., Hampson, R. F., Hynes, R. G., Jenkin, M. E., Rossi, M. J., and Troe, J.: Evaluated kinetic and photochemical data for atmospheric chemistry: Volume III - gas phase reactions of inorganic halogens, Atmos. Chem. Phys., 7, 981-1191, doi:10.5194/acp-7-981-2007, 2007.

Bloss, J. W., Nickolaisen, S. L., Salawitch, R. J., Friedl, R. R., and Sander, S. P.: Kinetics of the $\mathrm{ClO}$ self-reaction and $210 \mathrm{~nm}$ absorption cross section of the $\mathrm{ClO}$ dimer, J. Phys. Chem. A, 105, 11226-11239, 2001.

Burkholder, J. B., Orlando, J. J., and Howard, C. J.: Ultraviolet absorption cross sections of $\mathrm{Cl}_{2} \mathrm{O}_{2}$ between 210 and $410 \mathrm{~nm}, \mathrm{~J}$. Phys. Chem., 94, 687-695, 1990.

Chen, H. Y., Lien, C.-Y., Lin, W.-Y., Lee, Y. T., and Lin, J. J.: UV Absorption Cross Section of ClOOCl Are Consistent With Ozone Degradation Models, Science, 324, 781-784, 2009.

Chipperfield, M. P.: Multiannual simulations with a threedimensional chemical transport model, J. Geophys. Res., 104, 1781-1805, 1999.

Chipperfield, M. P.: New version of the TOMCAT/SLIMCAT offline chemical transport model: Intercomparison of stratospheric tracer experiments, Q. J. Roy. Meteorol. Soc., 132, 1179-1203, 2006.

Connor, B. J., Mooney, T., Barret, J. W., Solomon, P., Parrish, A., and Santee, M. L.: Comparison of $\mathrm{ClO}$ measurements from the Aura Microwave Limb Sounder to ground-based microwave measurements at Scott Base, Antarctica, in spring 2005, J. Geophys. Res., 112, D24S42, doi:10.1029/2007JD008792, 2007.

Cox, R. A. and Hayman, G. D.: The stability and photochemistry of dimers of the $\mathrm{ClO}$ radical and implications for Antarctic ozone depletion, Nature, 332, 796-800, 1988.

Feng, W., Chipperfield, M. P., Dorf, M., Pfeilsticker, K., and Ricaud, P.: Mid-latitude ozone changes: studies with a 3-D CTM forced by ERA-40 analyses, Atmos. Chem. Phys., 7, 2357-2369, doi:10.5194/acp-7-2357-2007, 2007.

Ferracci, V. and Rowley, D. M.: Kinetic and thermochemical studies of the $\mathrm{ClO}+\mathrm{ClO}+\mathrm{M} \leftrightarrows \mathrm{Cl}_{2} \mathrm{O}_{2}+\mathrm{M}$ reaction, Phys. Chem. Chem. Phys., 12, 11596-11608, 2010.

Frieler, K., Rex, M., Salawitch, R. J., Canty, T., Streibel, M., Stimpfle, R. M., Pfeilsticker, K., Dorf, M., Weisenstein, D. K., and Godin-Beekmann, S.: Toward a better quantitative understanding of polar stratospheric ozone loss, Geophys. Res. Lett., 33, L10812, doi:10.1029/2005GL025466, 2006.

Hassler, B., Bodeker, G. E., and Dameris, M.: Technical Note: A new global database of trace gases and aerosols from multiple sources of high vertical resolution measurements, Atmos. Chem. Phys., 8, 5403-5421, doi:10.5194/acp-8-5403-2008, 2008.

Huder, K. J. and DeMore, W. B.: Absorption Cross Sections of the ClO Dimer, J. Phys. Chem., 99, 3905-3908, 1995.

Kalnay, E., Kanamitsu, M., Kistler, R., Collins, W., Deaven, D., Gandin, L., Iredell, M., Saha, S., White, G., Woollen, J., Zhu, Y., Chelliah, M., Ebisuzaki, W., Higgins, W., Janowiak, J., Mo, K. C., Ropelewski, C., Wang, J., Leetmaa, A., Reynolds, R., Jenne, R., and Joseph, D.: The NCEP/NCAR 40-year reanalysis project, B. Am. Meteorol. Soc., 77, 437-471, 1996.

Molina, L. T. and Molina, M. J.: Production of the $\mathrm{Cl}_{2} \mathrm{O}_{2}$ from the Self-Reaction of the ClO Radical, J. Phys. Chem., 91, 433-436, 1987. 
Nickolaisen, S. L., Friedl, R. R., and Sander, S. P.: Kinetics and mechanism of the $\mathrm{ClO}-\mathrm{ClO}$ reaction - pressure and temperature dependence of the bimolecular and termolecular channels and thermal-decomposition of chlorine peroxide, J. Phys. Chem., 98, 155-169, 1994.

Papanastasiou, D. K., Papadimitriou, V. C., Fahey, D. W., and Burkholder, J. B.: UV Absorption Spectrum of the ClO Dimer $\left(\mathrm{Cl}_{2} \mathrm{O}_{2}\right)$ between 200 and $420 \mathrm{~nm}$, J. Phys. Chem. A, 113, 13711-13726, 2009.

Plenge, J., Kuehl, S., Vogel, B., Müller, R., Stroh, F., von Hobe, M., Flesch, R., and Ruehl, E.: Bond Strength of Chlorine Peroxide, J. Phys. Chem. A, 109, 6730-6734, 2005.

Pope, F. D., Hansen, J. C., Bayes, K. D., Friedl, R. R., and Sander, S. P.: Ultraviolet absorption spectrum of chlorine peroxide, ClOOCl, J. Phys. Chem. A, 111, 4322-4332, 2007.

Rodgers, C. D.: Inverse Methods For Atmospheric Sounding: Theory and Practice, World Scientific Publishing Co. Pte. Ltd., 2, 240, 2000.

Salawitch, R. J., Wofsy, S. C., Gottlieb, E. W., Lait, L. R., Newman, P. A., Schoeberl, M. R., Loewenstein, M., Podolske, J. R., Strahan, S. E., Proffitt, M. H., Webster, C. R., May, R. D., Fahey, D. W., Baumgardner, D., Dye, J. E., Wilson, J. C., Kelly, K. K., Elkins, J. W., and Chan, K. R.: Chemical loss of ozone in the Arctic polar vortex in the winter of 1991-1992, Science, 261, 1146-1149, 1993.

Sander, S. P., Friedl, R. R., Golden, D. M., Kurylo, M. J., Huie, R. E., Orkin, V. L., Moortgat, G. K., Ravishankara, A. R., Kolb, C. E., Molina, M. J., and Finlayson-Pitts, B. J.: Chemical Kinetics and Photochemical Data for Use in Atmospheric Studies, Evaluation Number 14, JPL Publication 02-25, Jet Propulsion Laboratory, Pasadena, CA, USA, 2003.

Sander, S. P., Friedl, R. R., Golden, D. M., Kurylo, M. J., Moortgat, G. K., Keller-Rudek, H., Wine, P. H., Ravishankara, A. R., Kolb, C. E., Molina, M. J., Finlayson-Pitts, B. J., Huie, R. E., and Orkin, V. L.: Chemical Kinetics and Photochemical Data for Use in Atmospheric Studies, Evaluation Number 15, JPL Publication 06-02, Jet Propulsion Laboratory, 2006.

Sander, S. P., Finlayson-Pitts, B. J., Friedl, R. R., Golden, D. M., Huie, R. E., Keller-Rudek, H., Kolb, C. E., Kurylo, M. J., Molina, M. J., Moortgat, G. K., Orkin, V. L., Ravishankara, A. R., and Wine, P. H.: Chemical Kinetics and Photochemical Data for Use in Atmospheric Studies, JPL Publication 09-31, Jet Propulsion Laboratory (Interim update to JPL06), 2009.

Santee, M. L., Sander, S. P., Livesey, N. J., and Froidevaux, L.: Constraining the chlorine monoxide $(\mathrm{ClO}) /$ chlorine peroxide $(\mathrm{ClOOCl})$ equilibrium constant from Aura Microwave Limb Sounder measurements of nighttime ClO, Proc. Natl. Acad. Sci. USA, 107, 6588-6593, 2010.

Schofield, R., Connor, B. J., Kreher, K., Johnston, P. V., and Rodgers, C. D.: The retrieval of profile and chemical information from ground-based UV-visible spectroscopic measurements, J. Quant. Spectrosc. Radiat. Transfer., 86, 115-131, 2004.
Schofield, R., Frieler, K., Wohltmann, I., Rex, M., von Hobe, M., Stroh, F., Koch, G., Peter, T., Canty, T., Salawitch, R., and Volk, C. M.: Polar Stratospheric Chlorine Kinetics from a SelfMatch Flight during SOLVE-II/EUPLEX, Geophys. Res. Lett., 35, L01807, doi:10.1029/2007GL031,740, 2008.

Solomon, P. M., Barrett, J. W., Connor, B. J., Zoonematkermani, S., Parrish, A., Lee, A., Pyle, J., and Chipperfield, M.: Seasonal observations of chlorine monoxide in the stratosphere over Antarctica during the 1996-1998 ozone holes and comparison with SLIMCAT three-dimensional model, J. Geophys. Res., 105, 28979-29001, 2000.

Solomon, P. M., Connor, B. J., Barrett, J. W., Mooney, T., Lee, A., and Parrish, A.: Measurements of stratospheric $\mathrm{ClO}$ over Antarctica in 1996-2000 and implications for $\mathrm{ClO}$ dimer chemistry, Geophys. Res. Lett., 29(15), 1708, doi:10.1029/2002GL015232, 2002.

Solomon, P. M., Barrett, J. W., Mooney, T., Connor, B. J., Parrish, A., and Siskind, D. E.: Rise and decline of active chlorine in the stratosphere, Geophys. Res. Lett., 33, L18807, doi:10.1029/2006GL027029, 2006.

SPARC: The Role of Halogen Chemistry in Polar Stratospheric Ozone Depletion: Report from the June 2008 Cambridge, UK Workshop for an Initiative under the Stratospheric Processes and Their Role in Climate (SPARC) Project of the World Climate Research Programme, Tech. rep., printed No. 33, 2009.

Stimpfle, R. M., Wilmouth, D. M., Salawitch, R. J., and Anderson, J. G.: First measurements of $\mathrm{ClOOCl}$ in the stratosphere: The coupling of $\mathrm{ClOOCl}$ and $\mathrm{ClO}$ in the Arctic polar vortex, J. Geophys. Res., 109, D03301, doi:10.1029/2003JD003811, 2004.

Trolier, M., Mauldin III, R. L., and Ravishankara, A. R.: Rate coefficient for the termolecular channel of the self-reaction of $\mathrm{ClO}$, J. Phys. Chem., 94, 4896-4907, 1990.

von Hobe, M., Grooß, J.-U., Müller, R., Hrechanyy, S., Winkler, U., and Stroh, F.: A re-evaluation of the $\mathrm{ClO} / \mathrm{Cl}_{2} \mathrm{O}_{2}$ equilibrium constant based on stratospheric in-situ observations, Atmos. Chem. Phys., 5, 693-702, doi:10.5194/acp-5-693-2005, 2005.

von Hobe, M., Salawitch, R. J., Canty, T., Keller-Rudek, H., Moortgat, G. K., Grooss, J.-U., Müller, R., and Stroh, F.: Understanding the kinetics of the $\mathrm{ClO}$ dimer cycle, Atmos. Chem. Phys., 7, 3055-3069, doi:10.5194/acp-7-3055-2007, 2007.

von Hobe, M., Stroh, F., Beckers, H., Benter, T., and Willner, H.: The UV/Vis absorption spectrum of matrix-isolated dichlorine peroxide, $\mathrm{ClOOCl}$, Phys. Chem. Chem. Phys., 11, 1571-1580, 2009.

Wilmouth, D. M., Hanisco, T. F., Stimpfle, R. M., and Anderson, J. G.: Chlorine-catalyzed ozone destruction: $\mathrm{Cl}$ atom production from ClOOCl photolysis, J. Phys. Chem. A, 113, 14099-14108, 2009. 